\title{
The Number of Ezrin-Expressing Lymphocytes Correlating with Tumor Cell Apoptosis and Prognosis of Human Gastric Carcinoma
}

\author{
Takeshi Matsubara*, Noriyuki Hirahara, Ryouji Hyakudomi, Yoshitsugu Tajima \\ The Department of Digestive and General Surgery, Faculty of Medicine, Shimane University, Izumo City, Japan \\ Email: ${ }^{*}$ nanadai@med.shimane-u.ac.jp
}

Received 10 July 2014; revised 25 August 2014; accepted 10 September 2014

Copyright (C) 2014 by authors and Scientific Research Publishing Inc.

This work is licensed under the Creative Commons Attribution International License (CC BY).

http://creativecommons.org/licenses/by/4.0/

(c) (i) Open Access

\begin{abstract}
Background: Ezrin is a linker protein between actin filaments and cell adhesion molecules, which plays an important role in cancer progression. There are only a few studies available that have investigated ezrin expression in different types of tumors. However, the prognostic importance of ezrin and its correlation with clinicopathological characteristics are yet to be delineated in gastric carcinoma. Methods: Specimens from 124 gastric carcinoma patients of T2 and T3 diseases treated in a defined period with curative operation were evaluated for ezrin, CD8 and cleaved caspase-3 expression by immunohistochemical methods. Results: Ezrin expression was detected in both cancer cells and interstitial cells (ISCs) infiltrated into the tumor. According to our criterion, 37 patients (29.8\%) were positive for ezrin expression and 87 (70.2\%) were negative. A significant correlation between ezrin expression and any of the clinicopathological characteristics could not be found. In Spearman-rank correlation test, a significant correlation was found between the number of ezrin-stained ISCs and apoptotic index (AI) of cancer cells. Also the AI of cancer cells was significantly higher in ezrin-positive group when compared with ezrin-negative group. Patients with ezrin-expressing tumors had a significantly better disease-free survival, and in multivariable analysis ezrin expression status remained significant as an independent prognostic factor. Conclusion: Taken together, our results suggest that ezrin expression may play a vital role in tumor apoptosis and that it can be a useful tool for therapeutic intervention.
\end{abstract}

\section{Keywords}

Ezrin, Apoptosis, Gastric Carcinoma, Prognosis

\footnotetext{
${ }^{*}$ Corresponding author.
}

How to cite this paper: Matsubara, T., Hirahara, N., Hyakudomi, R. and Tajima, Y. (2014) The Number of Ezrin-Expressing Lymphocytes Correlating with Tumor Cell Apoptosis and Prognosis of Human Gastric Carcinoma. Open Journal of Gastroenterology, 4, 310-320. http://dx.doi.org/10.4236/ojgas.2014.49045 


\section{Introduction}

Gastric carcinoma is the second most frequent malignancy in the world after lung carcinoma, with an estimated 876,000 new cases and 647,000 deaths reported in 2000 [1]. Despite improvements in the early diagnosis and better chemotherapeutic regimens, the outcome of this disease is dismal when diagnosed at an advanced stage [2]. It is urged that new molecular markers and treatment strategy are needed to design more effective therapy to treat these patients appropriately. To date, only a few tumor products have been identified which may serve as useful prognostic marker for invasive gastric cancers.

Ezrin is a member of the ERM (ezrin-radixin-moesin) family of proteins, which tethers a diverse set of membrane proteins to the intracellular actin filament and thus serves as a signal transducer. ERM proteins have been implicated in a myriad of cellular functions, ranging from regulation of cell extension such as filopodia, membrane ruffles, or microvilli formation to polarity, cytoskeletal organization, migration and growth [3]-[7]. Also ezrin participates in a signal transduction process of several cell survival factors, including Met receptor, epidermal growth factor receptor, phosphatidylinositol-3-kinase, protein kinase A and Rho pathways and thus controls cell survival, proliferation, and migration [8]-[10]. Ezrin is expressed at high levels in stomach, small intestine and kidney, and at very low levels in heart and brain [6]-[11].

Lymphocytes are often the major component of mononuclear cell infiltrates in many solid tumors. Tumorinfiltrating lymphocytes (TILs) have been considered to play an important role in the host defense mechanism against the growing neoplasm [12]. Results of several recently published articles indicate that $\mathrm{T}$ lymphocytes constitute the main component of TILs and are responsible for inducing apoptosis of cancer cells.

In recent years, an increasing number of studies have suggested that ezrin is involved both in the recognition of cognate antigen and execution of apoptosis of the target cells. T-cell recognition of cognate antigen is an essential step for T-cell proliferation and it has been shown that ezrin is involved in stimulation of T lymphocytes [13]. Also, ezrin is an integral part of the immunological synapse, which forms the interaction zone between the T-cell and its antigen-presenting cell [14]. These data show that ezrin in TILs plays an important role in the host defense mechanism.

The role of ezrin in cancer cells still remains elusive. Recent studies indicate that the role of ezrin in cancer cells is, to some extent, organ specific and it plays a differential role in tumor progression. While substantial evidences have identified ezrin as a proponent of cancer metastasis, only a few studies in contradiction have showed that over expression of ezrin in cancers is associated with noninvasive properties of cancer and predicts a good prognosis [15]. However, to the best of our knowledge, there are no studies about the role of ezrin in TILs. Moreover, correlation between ezrin expression and the clinicopathological characteristics and the impact of ezrin expression on patient prognosis are yet to be elucidated in gastric carcinoma.

In the current study, we seek to determine the expression of ezrin and apoptosis by immunohistochemistry in gastric carcinoma samples.

\section{Methods}

\subsection{Patients and Samples}

Between January 1995 to December 2000, 124 consecutive patients with either T2 or T3 gastric adenocarcinoma who had a curative resection were included in the study. There were 65 patients with T2 and 59 patients with T3 disease. The criteria considered for curative resection were the complete removal of primary gastric tumor, dissection of the regional lymph nodes and no remaining macroscopic tumors. All selected patients had tumors with no known distant metastases at the time of surgery and had received no preoperative radiotherapy or chemotherapy. No other previous or concomitant primary cancer was present. All tumors were classified using the UICC pTNM categories. All patients had a complete follow-up. Data obtained at regular follow-up visits in the outpatient department were compiled into a database specially designed for patients with gastric carcinoma. In case of any recurrence, the exact date of disease recurrence was collected from the referring doctor or from the doctor who attended the patient for the first time for diagnosis of the disease recurrence.

\subsection{Immunohistochemical Detection of Ezrin, CD8 and Cleaved Caspase-3 Expressions}

Serial sections $(5 \mu \mathrm{m})$ of formalin-fixed, paraffin-embedded tissues were obtained and stained using the avidinbiotin-peroxidase complex method. Briefly, sections were deparaffinized in xylene and rehydrated in graded al- 
cohol solutions. Antigen retrieval with $10 \mathrm{mmol} / \mathrm{L}$ citrate buffer $(\mathrm{pH}) 6.0$ for ezrin and $\mathrm{CD} 8$ staining and with 1 $\mathrm{mm}(\mathrm{pH}) 8.0$ EDTA for cleaved caspase-3 staining was done. The sections were then incubated in $3 \% \mathrm{H}_{2} \mathrm{O}_{2}$ for $30 \mathrm{~min}$ to block the endogenous peroxidase activity. Slides were treated with normal serum obtained from the same species in which the secondary antibody was developed for $30 \mathrm{~min}$ to block the non-specific staining. Subsequently, slides were incubated with the primary antibodies 1:200 dilutions for overnight at 4 degree for ezrin, 1:50 dilution for overnight at 4 degree for $\mathrm{CD} 8$, and 1:250 dilutions for overnight at 4 degree for cleaved caspase-3). Mouse monoclonal antibody against ezrin (Zymed Laboratories Inc., South San Francisco, USA), mouse monoclonal antibody against CD8 (Novocastra Laboratories, Ltd., Newcastle, UK), and rabbit monoclonal antibody against cleaved caspase-3 (Cell Signaling Technology, Inc., Beverly, MA) were used in this study. Immunohistochemical staining was done using the SAB mouse/rabbit kit (Nichirei Co., Tokyo, Japan) according to the manufacturer's instruction. Washing in PBS for ezrin and CD8 staining and in $0.075 \%$ Briji detergent/PBS for cleaved caspase-3 staining followed all steps except the step involving the blocking peptide. Diaminobenzidine was used as the chromogen for ezrin and cleaved caspase-3 staining and aminoethylcalbasol was used for CD8 staining. Sections were counterstained with hematoxylin. Appropriate positive and negative control slides were included with each staining run.

\subsection{Evaluation of Ezrin Immunostaining and CD8+ Cells}

Evaluation of immunohistochemical staining was performed blindly and independently by two of the authors (Matsubara, T. and Hirahara, N.). Immunoreactivity of ezrin in tumor cells was evaluated using the intensity and the extent of ezrin staining as described before [16]. The intensity was scored on a scale of 0 to 3 , in which $0=$ negative staining, $1=$ weakly positive staining, 2 = moderately positive staining, and $3=$ strongly positive staining. The extent of positive staining was estimated and scored on a scale of 0 to 4 , in which $0=$ negative, $1=$ $1 \%$ to $25 \%$ positive cells, $2=26 \%$ to $50 \%, 3=51 \%$ to $75 \%$ and $4=76 \%$ to $100 \%$. The sum of the intensity and extent of staining scores was used as the final ezrin expression score in cancer. An arbitrary cut off value between 4 and 5 had the best predictive value for ezrin and was used in this study. Tumors with scores from 0 to 5 were considered to be low ezrin group in cancer, and those with 6 and 7 were considered to be high ezrin group in cancer.

Interstitial cells (ISCs: lymphocytes and other inflammatory cells) were evaluated in the stroma of the tumor or around the tumor, but not associated with an area of ulceration or tumor necrosis. Polymorphonuclear and lymphoid follicle cells were excluded in the scoring process. To count the number of ezrin positive lymphocyte and CD8+ T-cells, at least 10 representative areas without necrosis and consisting 1000 cancer cells were counted for each sample with high-power fields (HPF: 400×). The mean of the numbers of ezrin-stained ISCs for all tumors was used as the cut-off value to stratify patients into high and low ezrin expression groups.

Tumors were considered to be positive for ezrin when ezrin expression was high in both cancer cells and ISCs.

\subsection{Determination of Apoptotic Index}

The numbers of cleaved caspase- 3 stained cancer cells and interstitial cells were counted separately. To determine the Apoptotic Index (AI) of cancer cells, at least 10 representative areas without necrosis and consisting 1000 cancer cells were counted. In the same manner of tumor AI, to determine the AI of ISCs at least 5 representative areas and consisting 1000 ISCs were counted. The apoptotic index (AI) was expressed as the percentage of cleaved caspase-3 positive cells.

\subsection{Statistical Analysis}

Chi-square tests examined relationships between categorical variables. Mann-Whitney $U$ test or $t$-tests were used to compare continuous variables. Spearman-rank correlation test was used to investigate relationship between two continuous variables. Survival curves were plotted using the Kaplan-Meier method and the statistical significance between groups was determined by the log-rank test. Independent variables predicting survival were evaluated by multiple stepwise regression analysis using the Cox model. StatView 5.0J (Abacus Concepts, Berkley, CA) software was used for data analysis. 


\section{Results and Discussion}

\subsection{Expression of Ezrin, CD8+ T Cells and Caspase-3}

The characteristic patterns of ezrin immunoreactivity are shown in Figure 1(A) and Figure 1(B). As it is well recognized, strong ezrin immunoreactivity was confirmed in the parietal cells of gastric epithelium. In most of the gastric carcinoma samples, ezrin expression was distributed homogeneously inside the cytoplasm of cancer cells. Occasionally, dots of immunostained areas condensed below the cell membrane were noticed (Figure 1(A)). Also strong ezrin immunoreactivity was recognized in the interstitial cells (ISCs) of the tumoral stroma (Figure 1(B)) and peritumoral lymphoid follicles.

To characterize these ezrin-stained ISCs further, we stained serial tissue sections with anti-CD8 antibody. On serial section, CD8+ T-cells were localized in the same area of mononuclear ezrin-stained cells (Figure 2(A), Figure 2(B)). The number of CD8+ T-cells was significantly higher in ezrin positive group when compared with negative group (median range: $26(2-136)$ vs. $16(0-103), p=0.03$; Mann-Whitney $U$ test) (Table 1$)$. Thus the ezrin-stained ISCs are most likely to be CD8+ T-cells. Immunoreactivity of cleaved caspase- 3 was confirmed inside the cytoplasm of cells (Figure 3(A)). Scattered apoptotic cells (cleaved caspase-3) were noticed in both cancer cells and among the peritumoral infiltrating cells (Figure 3(B)).

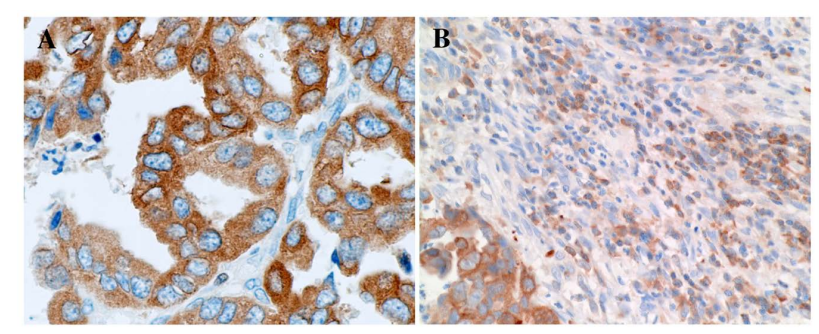

Figure 1. Representative sections showing immunohistochemical expression of ezrin (Original magnification 400×): (A) In most of the gastric carcinoma samples, ezrin expression was distributed homogeneously inside the cytoplasm of cancer cells. Occasionally, dots of immunostained areas condensed below the cell membrane were noticed; (B) Strong ezrin immunoreactivity was recognized in interstitial cells (ISCs) infiltrated into cancer.

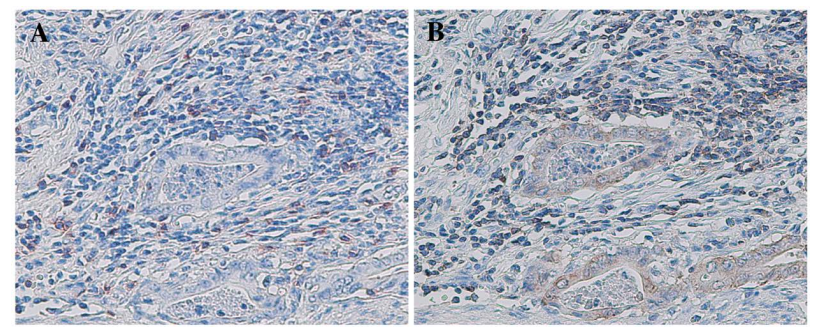

Figure 2. Serial sections showing immunohistochemical expressions of (A) CD8 and (B) ezrin. CD8 positive cells were localized in almost the same area of ezrin positive ISCs (Original magnification $200 \times$ ).

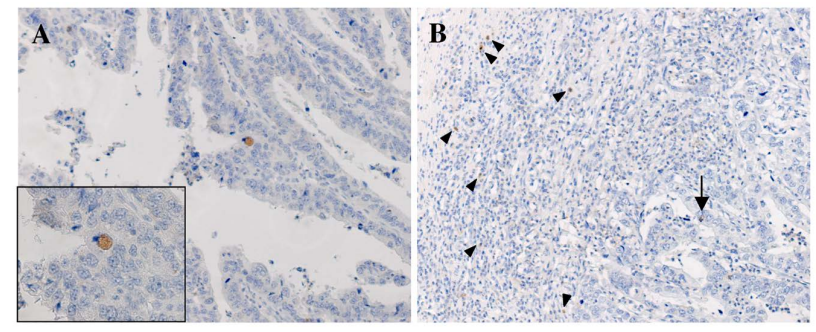

Figure 3. Apoptotic cells are shown in the tumor (A) and among the peritumoral infiltrating cells (B) by using an anti-leaved caspase-3 (arrow: apoptotic cancer cells; arrow-head: apoptotic peritumoral infiltrating cells) (Original magnification $100 \times$ ). 
Table 1. Ezrin expression and clinicopathological factors in gastric carcinoma.

\begin{tabular}{|c|c|c|c|}
\hline \multirow[b]{2}{*}{ Variable } & \multicolumn{2}{|c|}{ Ezrin expression } & \multirow[b]{2}{*}{$P$ value } \\
\hline & $\begin{array}{l}\text { Positive group } \\
\quad(\mathrm{n}=37)\end{array}$ & $\begin{array}{l}\text { Negative group } \\
\quad(\mathrm{n}=87)\end{array}$ & \\
\hline \multicolumn{4}{|l|}{ Gender } \\
\hline Male & 19 & 58 & $0.16^{\mathrm{a}}$ \\
\hline Female & 18 & 29 & \\
\hline \multicolumn{4}{|l|}{ Tumor size } \\
\hline$<5 \mathrm{~cm}$ & 15 & 35 & $0.23^{\mathrm{a}}$ \\
\hline$\geq 5 \mathrm{~cm}$ & 22 & 52 & \\
\hline \multicolumn{4}{|l|}{ Age } \\
\hline$<65 \mathrm{yrs}$ & 11 & 37 & $0.99^{\mathrm{a}}$ \\
\hline$\geq 65 \mathrm{yrs}$ & 26 & 50 & \\
\hline \multicolumn{4}{|l|}{ Lauren's classification } \\
\hline Intestinal type & 12 & 25 & $0.85^{\mathrm{a}}$ \\
\hline Diffuse type & 25 & 62 & \\
\hline \multicolumn{4}{|l|}{ T stage } \\
\hline $\mathrm{T} 2$ & 20 & 45 & $0.85^{\mathrm{a}}$ \\
\hline $\mathrm{T} 3$ & 17 & 42 & \\
\hline \multicolumn{4}{|l|}{$\mathrm{N}$ stage } \\
\hline Negative & 32 & 72 & $0.99^{\mathrm{a}}$ \\
\hline Positive & 5 & 15 & \\
\hline \multicolumn{4}{|l|}{ Lymph vessel invation } \\
\hline Negative & 10 & 22 & $0.99^{\mathrm{a}}$ \\
\hline Positive & 27 & 63 & \\
\hline Unknown & & 2 & \\
\hline \multicolumn{4}{|l|}{ Blood vessel invasion } \\
\hline Negative & 10 & 26 & $0.99^{\mathrm{a}}$ \\
\hline Positive & 25 & 59 & \\
\hline Unknown & 2 & 2 & \\
\hline \multicolumn{4}{|l|}{ Histological grade } \\
\hline Well differentiated & 6 & 21 & $0.48^{\mathrm{a}}$ \\
\hline Others & 31 & 66 & \\
\hline \multicolumn{4}{|c|}{ CD8+ T-cell (cell count) } \\
\hline$($ mean $\pm \mathrm{SD})$ & $35.5 \pm 32.2$ & $24.5 \pm 24.5$ & $0.03^{\mathrm{b}}$ \\
\hline \multicolumn{4}{|l|}{ Apoptotic Index } \\
\hline$($ mean $\pm \mathrm{SD})$ & $1.53 \pm 1.48$ & $0.97 \pm 0.82$ & $0.04^{\mathrm{b}}$ \\
\hline
\end{tabular}

\subsection{Ezrin Expression and Clinicopathological Findings}

Ezrin expression was positive in 59 (47.6\%) and 57 (46\%) patients and negative in $65(52.4 \%)$ and $67(54.0 \%)$ patients in cancer cells and ISCs, respectively. A significant direct correlation was noticed between the ezrin expression score in cancer cells and the numbers of ezrin-stained ISCs $(\mathrm{P}<0.001, \rho=0.322$, Spearman-rank test). According to our criterion as described in the Methods section, 37 patients $(29.8 \%)$ were positive for ezrin expression and 87 (70.2\%) were negative. A significant correlation between ezrin expression and any of the clini- 
copathological characteristics could not be found this study (Table 1). This was true when ezrin expression in cancer cells and in ISCs were evaluated separately (data not shown).

\subsection{Ezrin and Apoptosis}

The mean \pm SD of AI of cancer cells and ISCs were $1.23 \pm 1.20$ and $0.81 \pm 0.56$, respectively (Table 1 ). The tumor AI was significantly higher in ezrin positive group than in ezrin negative group (median range: $1.2 \%$ $(0.08 \%-4.79 \%)$ vs. $0.8 \%(0.1 \%-4.2 \%), p=0.04$; Mann-Whitney U test) (data not shown). In Spearman-rank correlation test, a significant $(\mathrm{p}=0.0198$ and $\mathrm{p}=0.21)$ correlation was found only between the number of ezrinstained ISCs and AI of cancer cells (Figure 4) whereas a similar correlation could not be found between ezrin expression score in cancer and AI of ISCs $(\mathrm{p}=0.937)$. Still more, correlation between the number of ezrinstained ISCs and the AI of ISCs could not found signification in Spearman-rank correlation test $(p=0.0656)$.

\subsection{Long-Term Survival}

The $1 \mathrm{yr}, 3 \mathrm{yr}$ and $5 \mathrm{yr}$ disease free survival (DFS) were 94.4\%, 94.4\% and $89.2 \%$, and $82.5 \%, 68.7 \%$ and $65.8 \%$, in patients with ezrin positive group and negative group, respectively (Figure 5(a)). Patients with ezrin negative tumors had a significantly worse DFS ( $\mathrm{p}=0.007$, log rank test) and had only a marginal association with the overall survival (OS) $(\mathrm{p}=0.071, \log$ rank test). Moreover, significant associations were noticed between patient's prognosis and ezrin expression in both cancer cells (DFS, $p=0.041$ and OS, $p=0.018$ ) and ISCs (DFS, $p=0.018$ and OS, $p=0.108$ ) (Figure 5(b) and Figure 5(c) for OS data not shown). Other factors influencing the DFS rate by the univariate analysis were T classification ( 2 vs. $3 ; \mathrm{p}<0.01$ ), $\mathrm{N}$ classification (negative $v s$. positive; $\mathrm{p}<0.01$ ), lymph vessel invasion (negative $v s$. positive; $\mathrm{p}=0.04$ ), and intraoperative blood loss (low vs. high; $p=0.03$ ) (Table 2). Thus, we used the mean of the amount of blood loss as the cut-off point.

The independent risk factors for DFS as determined by the multivariable analysis were $\mathrm{N}$ classification (hazard ratios $=5.9$ ), T classification (hazard ratios $=4.8$ ), and ezrin expression (hazard ratios $=4.4$ ) (Table 3 ).

\subsection{Discussion}

Cellular ezrin plays a vital role in maintaining various biological functions of cells including formation of cellcell contact and transduction of cell signals from cell membrane to actin filaments. However, the precise role of ezrin in carcinogenesis and progression of cancer is still debated. Most of the studies dealing with ezrin expression on clinical materials showed that overexpression of ezrin in cancers are associated with metastatic phenotype and a worse patient prognosis. Contrary to these findings, results of this study showed that an enhanced expression of ezrin is associated with an improved prognosis in gastric cancer. The improved prognostic effect of ezrin could be explained in terms of an association of ezrin with the tumor suppressive effect and active participation of ezrin in tumor cell apoptosis. The improved DFS in patients with high ezrin expression could be

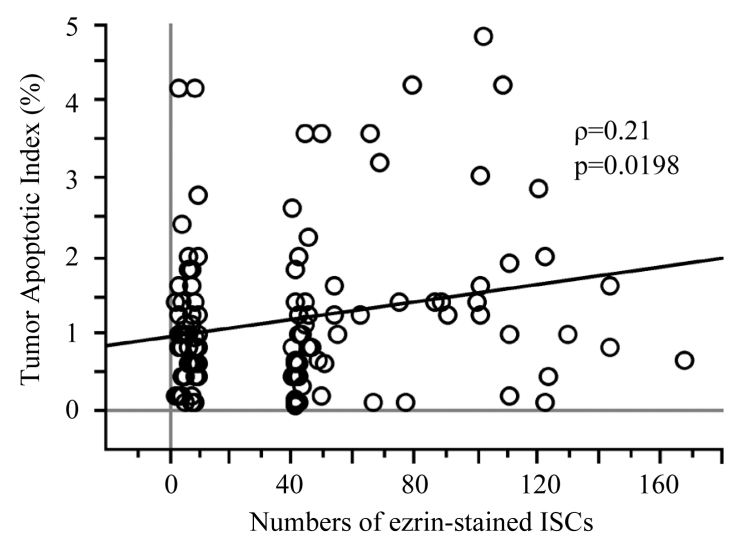

Figure 4. The correlation between the numbers of ezrinstained ISCs and tumor apoptotic index was shown. A significant direct correlation was found $(\rho=0.21, \mathrm{P}=$ 0.0198; Spearman rank correlation coefficient test). 

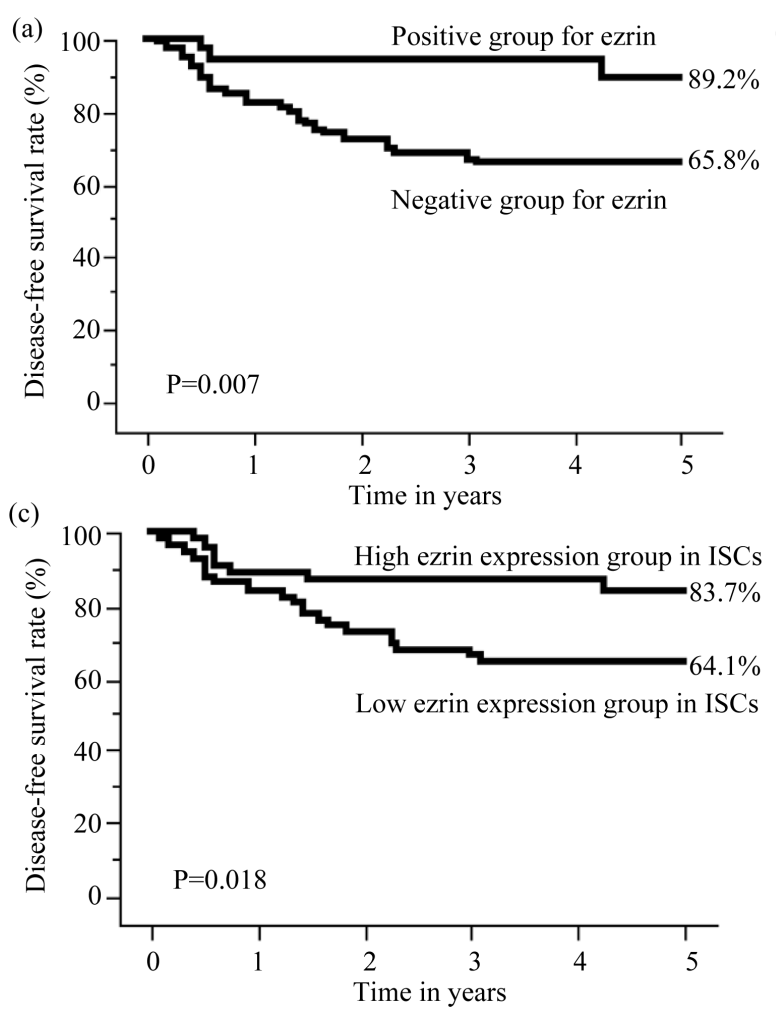

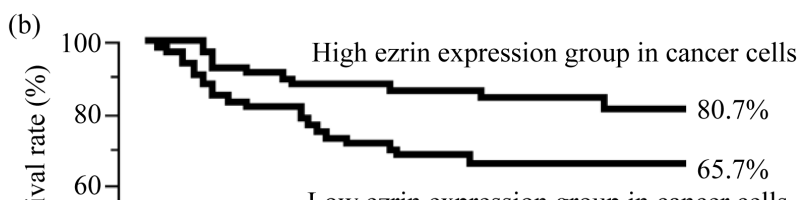

Low ezrin expression group in cancer cells

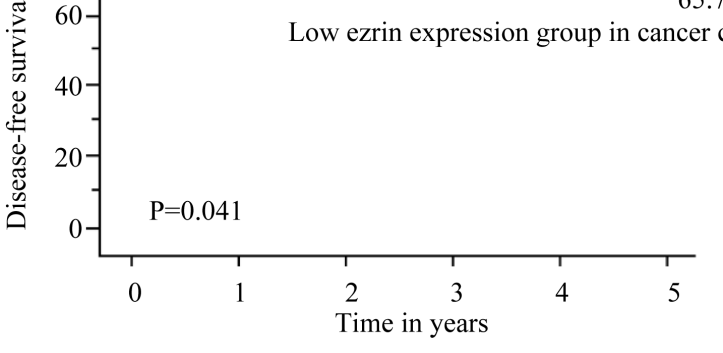

Figure 5. The impact of ezrin expression on patients' survival as evaluated by the Kaplan-Meier method is shown: (a) tumor ezrin expression; (b) ezrin expression in only cancer cells and (c) ezrin expression in only ISCs.

partially attributable to the tumor suppressive role of the ERM family of proteins. Both band 4:1 and ezrin have been shown to interact in a co-precipitate complex with the murine form of $\mathrm{hDlg}$, a homologue of the Dorsophilia Dlg tumor suppressor protein [17]. Also merlin, encoded by neurofibromatosis type 2 (NF2) genes, is closely related to the ERM family of proteins and plays a tumor suppressor role [18]. Another member of the ERM family proteins, DAL-1 (differentially expressed in adenocarcinoma of the lung), is also recognized as a tumor suppressor gene [19]. Moreover, deletion of chromosome 6q, where ezrin is located, is frequently seen in prostate cancer and may only indicate that it serves as a tumor suppressor gene. Indeed, Pang et al. showed a higher expression of ezrin in high-grade prostatic epithelial neoplasia than in invasive cancers and the authors concluded that ezrin may play a vital role in strengthening the cells' ability to retain their normal growth pattern [20]. In stomach, ezrin is constitutively expressed in parietal cells of gastric epithelium and plays a vital role in acid secretion, and thus it may have a significant role in maintaining the morphological organization of gastric cancer cells. Taken together, results of these studies may indicate that ezrin plays a pivotal role in tumor suppression and this might be to some extent organ specific.

In recent years, an increasing number of studies have suggested a possible involvement of ezrin in apoptosis and, therefore, we searched the correlation between ezrin expression and tumor cell apoptosis in gastric carcinoma samples. Helander et al. [21] produced the first concrete evidence of a possible significant role of ezrin in apoptosis. In their study, the authors showed that transfected ezrin redistributed ICAM-2 to newly formed cellular protrusions (uropod) on the surface of thymoma cells, which then became the target of the natural killer cells. Also Shen et al. [22] showed that apoptosis induced by arsenic trioxide in an esophageal epithelial cell line caused translocation of ezrin from membrane to the cytoplasm. As shown in the Results section, a significant direct correlation was found between tumor ezrin expression and apoptosis of cancer cells in our study.

In general, the Fas/FasL system mediates T-cell cytotoxicity, and thus, FasL-positive T-cells eliminate Faspositive cancer cells by inducing apoptosis. Kondo et al. [23] showed that in Fas-ligand induced apoptosis, ezrin translocates from microvilli to the cytoplasm and, therefore, connects Fas to the cytoskeletal structure during apoptosis. Moreover, the Fas/ezrin interaction is a direct one and also specific since other molecules of the ERM 
Table 2. Univariate analysis of prognostic factors in patients with gastric carcinoma as evaluated by disease-free survival and overall surtival.

\begin{tabular}{|c|c|c|c|c|c|}
\hline \multirow{2}{*}{ Variable } & \multirow{2}{*}{ Number } & \multicolumn{2}{|c|}{ Disease-free survival } & \multicolumn{2}{|c|}{ Overall survival } \\
\hline & & $\mathrm{RR}(95 \% \mathrm{CI})$ & $\mathrm{P}$ value & $\mathrm{RR}(95 \% \mathrm{CI})$ & $\mathrm{P}$ value \\
\hline \multicolumn{6}{|l|}{ Gender } \\
\hline Male & 77 & $1.7(0.8-3.7)$ & 0.18 & $1.3(1.1-4.8)$ & 0.03 \\
\hline Female & 47 & & & & \\
\hline \multicolumn{6}{|l|}{ Tumor size } \\
\hline$<5 \mathrm{~cm}$ & 50 & & & & \\
\hline$\geq 5 \mathrm{~cm}$ & 74 & $2.2(1.0-4.9)$ & 0.05 & $1.7(0.8-3.3)$ & 0.15 \\
\hline \multicolumn{6}{|l|}{ Age } \\
\hline$<65$ yrs & 48 & & & & \\
\hline$\geq 65 \mathrm{yrs}$ & 76 & $1.5(0.7-3.2)$ & 0.30 & $2.0(1.0-4.0)$ & 0.07 \\
\hline \multicolumn{6}{|l|}{ T stage } \\
\hline $\mathrm{T} 2$ & 65 & & & & \\
\hline $\mathrm{T} 3$ & 59 & $5.0(2.1-12) .4)$ & $<0.01$ & $2.3(1.2-4.4)$ & 0.02 \\
\hline \multicolumn{6}{|l|}{$\mathrm{N}$ stage } \\
\hline Negative & 104 & & & & \\
\hline Positive & 20 & $5.6(2.7-11.5)$ & $<0.01$ & $3.4(1.3-8.7)$ & 0.01 \\
\hline \multicolumn{6}{|l|}{ Lymph vessel invasion } \\
\hline Negative & 32 & & & & \\
\hline Positive & 90 & $3.4(1.0-11.2)$ & 0.01 & $1.5(0.7-3.5)$ & 0.32 \\
\hline Unknown & 2 & & & & \\
\hline \multicolumn{6}{|l|}{ Blood vessel invasion } \\
\hline Negative & 36 & & & & \\
\hline Positive & 84 & $2.4(0.9-6.3)$ & 0.07 & $1.8(0.8-3.9)$ & 0.15 \\
\hline Unknown & 4 & & & & \\
\hline \multicolumn{6}{|l|}{ Histological grade } \\
\hline Well differentiated & 27 & & & & \\
\hline Others & 97 & $1.0(0.4-2.5)$ & 0.93 & $0.5(0.3-1.0)$ & 0.06 \\
\hline \multicolumn{6}{|c|}{ Intraoperative blood loss } \\
\hline Low & 93 & & & & \\
\hline High & 31 & $3.0(1.2-7.9)$ & 0.03 & $2.1(0.9-4.7)$ & $<0.01$ \\
\hline \multicolumn{6}{|l|}{ Ezrin expression } \\
\hline Negative group & 87 & $4.5(1.4-14.7)$ & 0.01 & $2.1(0.9-4.7)$ & 0.08 \\
\hline Positive group & 37 & & & & \\
\hline
\end{tabular}

$\mathrm{P}$ value $<0.05$ according to logrank test; $95 \% \mathrm{CI}$ : $95 \%$ confidence interval; RR: risk ratio.

Table 3. Multivariate analysis of prognostic factors in patients with gastric carcinoma as evaluated by disease-free survival.

\begin{tabular}{|c|c|c|c|}
\hline Parameter & Chi-square value & $\mathrm{RR}(95 \% \mathrm{CI})$ & $P$ value \\
\hline N stage (Negative/Positive) & 16.2 & $5.9(2.5-13.9)$ & $<0.01$ \\
\hline T stage $(\mathrm{T} 2 / \mathrm{T} 3)$ & 6.2 & $4.8(1.4-16.6)$ & 0.01 \\
\hline Ezrin expression (Positive/Negative) & 7.9 & $4.4(1.6-12.3)$ & $<0.01$ \\
\hline Intraoperative blood loss (Low/High) & 1.9 & $2.1(0.7-6.2)$ & 0.16 \\
\hline Gender (Female/Male) & 1.4 & $1.7(0.7-4.3)$ & 0.23 \\
\hline Lymph vessel invasion (Negative/Positive) & 0.3 & $1.4(0.4-5.8)$ & 0.61 \\
\hline Tumor size $(\geq 5 \mathrm{~cm} /<5 \mathrm{~cm})$ & 0.4 & $1.4(0.5-3.7)$ & 0.54 \\
\hline Age $(\geq 65 \mathrm{yrs} /<65 \mathrm{yrs})$ & 0.0 & $1.1(0.5-2.5)$ & 0.83 \\
\hline Blood vessel invasion (Negative/Positive) & 0.0 & $1.0(0.4-3.0)$ & 0.93 \\
\hline
\end{tabular}

P value $<0.05$ according to logrank test; $95 \% \mathrm{CI}$ : 95\% confidence interval; RR: risk ratio. 
family including moesin and radixin are not able to bind to Fas. Thus, ezrin may have a major role in connecting actin to both Fas and downstream molecules of the Fas-induced apoptosis cascade.

In this study, ezrin expression was observed not only in cancer cells, but also in ISCs as showed in the Results section (Figure 1(A), Figure 1(B)). It seems that ezrin is involved both in the recognition of cognate antigen and execution of apoptosis of the target cells. T-cell recognition of cognate antigen is an essential step for T-cell proliferation and it has been shown that ezrin is involved in stimulation of T lymphocytes [13]. Ezrin is an integral part of the immunological synapse, which forms the interaction zone between the T-cell and its antigen presenting cell [14]. A similar interaction occurs between natural killer (NK) cells and their target tumor cells. It has been speculated that NK cells may distinguish malignant cells through ezrin-controlled distribution of cell adhesion molecules. Ramoni et al. showed that ezrin co-localized with perforin granules in the NK cell-to-target contact site. It seems that ezrin steer the perforin granules to the uropods of NK cells [24]. There are several studies, which have already established a correlation between the grade of peritumoral lymphocytes infiltration and prognosis of gastric carcinoma [25]-[27]. In our study, the ezrin stained ISCs were characterized as mainly CD8+ T-cells on serial section. Therefore, results of our study may indicate that presence of ezrin-stained lymphocytes is a prerequisite for enhanced tumor cell apoptosis in gastric carcinoma. It is worth mentioning that most of the in vivo studies, evaluating the effect of ezrin on tumor growth and metastasis, used immune compromised mice (SCID mice or nude mice) and, therefore, immune competent cells had a minor role in resisting metastasis in these models. In a very recent study, Elliot et al. used a syngeneic mouse breast cancer metastasis model and the authors concluded that overexpression of ezrin alone is not sufficient to induce metastasis and multiple pathways are involved in the metastatic cascade [28]. Therefore further studies are to be performed to reveal the exact role of ezrin in apoptosis in appropriate experimental model.

\section{Conclusion}

To the best of our knowledge, this is the first study indicating that besides the role of ezrin in metastasis it may have a significant impact on tumor cell apoptosis induced by the ezrin-positive ISCs. An intensive postoperative follow-up may be necessary for patients who have tumors with a negative ezrin expression. However, future prospective studies are mandatory to evaluate the prognostic significance of ezrin in gastric carcinoma.

\section{Competing Interests}

The authors declare that they have no competing interests.

\section{Authors' Contributions}

Matsubara, T. was the lead author and carried out the all studies, participated in the sequence alignment and drafted the manuscript. Hirahara, N. and Hyakudomi, R. have been involved in drafting the manuscript and revising it critically for important intellectual content. Tajima Y. has given final approval of the version to be published. All authors read and approved the final manuscript.

\section{References}

[1] Parkin, D.M. (2001) Global Cancer Statistics in the Year 2000. The Lancet Oncology, 2, 533-543. http://dx.doi.org/10.1016/S1470-2045(01)00486-7

[2] Dhar, D.K., Kubota, H., Tachibana, M., Kinugasa, S., Masunaga, R., Shibakita, M., Kohno, H. and Nagasue, N. (2001) Prognosis of T4 Gastric Carcinoma Patients: An Appraisal of Aggressive Surgical Treatment. Journal of Surgical Oncology, 76, 278-282. http://dx.doi.org/10.1002/jso.1046

[3] Tsukita, S. and Yonemura, S. (1997) ERM (Ezrin/Radixin/Moesin) Family: From Cytoskeleton to Signal Transduction. Current Opinion in Cell Biology, 9, 70-75. http://dx.doi.org/10.1016/S0955-0674(97)80154-8

[4] Vaheri, A., Carpén, O., Heiska, L., Helander, T.S., Jääskeläinen, J., Majander-Nordenswan, P., Sainio, M., Timonen, T. and Turunen, O. (1997) The Ezrin Protein Family: Membrane-Cytoskeleton Interactions and Disease Associations. Current Opinion in Cell Biology, 9, 659-666. http://dx.doi.org/10.1016/S0955-0674(97)80119-6

[5] Yonemura, S., Hirao, M., Doi, Y., Takahashi, N., Kondo, T., Tsukita, S. and Tsukita, S. (1998) Ezrin/Radixin/Moesin (ERM) Proteins Bind to a Positively Charged Amino Acid Cluster in the Juxta-Membrane Cytoplasmic Domain of CD44, CD43, and ICAM-2. The Journal of Cell Biology, 140, 885-895. http://dx.doi.org/10.1083/jcb.140.4.885 
[6] Tsukita, S., Oishi, K., Sato, N., Sagara, J., Kawai, A. and Tsukita, S. (1994) ERM Family Members as Molecular Linkers between the Cell Surface Glycoprotein CD44 and Actin-Based Cytoskeletons. The Journal of Cell Biology, 126, 391-401. http://dx.doi.org/10.1083/jcb.126.2.391

[7] Heiska, L., Alfthan, K., Grönholm, M., Vilja, P., Vaheri, A. and Carpén, O. (1998) Association of Ezrin with Intercellular Adhesion Molecule-1 and -2 (ICAM-1 and ICAM-2). Regulation by Phosphatidylinositol 4,5-Bisphosphate. The Journal of Biological Chemistry, 273, 21893-21900. http://dx.doi.org/10.1074/jbc.273.34.21893

[8] Gautreau, A., Poullet, P., Louvard, D. and Arpin, M. (1999) Ezrin, a Plasma Membrane-Microfilament Linker, Signals Cell Survival through the Phosphatidylinositol 3-Kinase/Akt Pathway. Proceedings of the National Academy of Sciences of the United States of America, 96, 7300-7305. http://dx.doi.org/10.1073/pnas.96.13.7300

[9] Dransfield, D.T., Bradford, A.J., Smith, J., Martin, M., Roy, C., Mangeat, P.H. and Goldenring, J.R. (1997) Ezrin Is a Cyclic AMP-Dependent Protein Kinase Anchoring Protein. The EMBO Journal, 16, 35-43. http://dx.doi.org/10.1093/emboj/16.1.35

[10] Mackay, D.J., Esch, F., Furthmayr, H. and Hall, A. (1997) Rho- and Rac-Dependent Assembly of Focal Adhesion Complexes and Actin Filaments in Permeabilized Fibroblasts: An Essential Role for Ezrin/Radixin/Moesin Proteins. The Journal of Cell Biology, 138, 927-938. http://dx.doi.org/10.1083/jcb.138.4.927

[11] Berryman, M., Franck, Z. and Bretscher, A. (1993) Ezrin Is Concentrated in the Apical Microvilli of a Wide Variety of Epithelial Cells Whereas Moesin Is Found Primarily in Endothelial Cells. Journal of Cell Science, 105, 1025-1043.

[12] Rosenberg, S.A. (1996) The Immunotherapy of Solid Cancers Based on Cloning the Genes Encoding Tumor-Rejection Antigens. Annual Review of Medicine, 47, 481-491. http://dx.doi.org/10.1146/annurev.med.47.1.481

[13] Thuillier, L., Hivroz, C., Fagard, R., Andreoli, C. and Mangeat, P. (1994) Ligation of CD4 Surface Antigen Induces Rapid Tyrosine Phosphorylation of the Cytoskeletal Protein Ezrin. Cellular Immunology, 156, 322-331. http://dx.doi.org/10.1006/cimm.1994.1178

[14] Roumier, A., Olivo-Marin, J.C., Arpin, M., Michel, F., Martin, M., Mangeat, P., Acuto, O., Dautry-Varsat, A. and Alcover, A. (2001) The Membrane-Microfilament Linker Ezrin Is Involved in the Formation of the Immunological Synapse and in T Cell Activation. Immunity, 15, 715-728. http://dx.doi.org/10.1016/S1074-7613(01)00225-4

[15] Moilanen, J., Lassus, H., Leminen, A., Vaheri, A., Bützow, R. and Carpén, O. (2003) Ezrin Immunoreactivity in Relation to Survival in Serous Ovarian Carcinoma Patients. Gynecologic Oncology, 90, 273-281. http://dx.doi.org/10.1016/S0090-8258(03)00262-2

[16] Hira, E., Ono, T., Dhar, D.K., El-Assal, O.N., Hishikawa, Y., Yamanoi, A. and Nagasue, N. (2005) Overexpression of Macrophage Migration Inhibitory Factor Induces Angiogenesis and Deteriorates Prognosis after Radical Resection for Hepatocellular Carcinoma. Cancer, 103, 588-598. http://dx.doi.org/10.1002/cncr.20818

[17] Lue, R.A., Brandin, E., Chan, E.P. and Branton, D. (1996) Two Independent Domains of hDlg Are Sufficient for Subcellular Targeting: The PDZ1-2 Conformational Unit and an Alternatively Spliced Domain. Journal of Cell Biology, 135, 1125-1137. http://dx.doi.org/10.1083/jcb.135.4.1125

[18] Trofatter, J.A., MacCollin, M.M., Rutter, J.L., Murrell, J.R., Duyao, M.P., Parry, D.M., Eldridge, R., Kley, N., Menon, A.G., Pulaski, K., et al. (1993) A Novel Moesin-, Ezrin-, Radixin-Like Gene Is a Candidate for the Neurofibromatosis 2 Tumor Suppressor. Cell, 72, 791-800. http://dx.doi.org/10.1016/0092-8674(93)90406-G

[19] Tran, Y.K., Bögler, O., Gorse, K.M., Wieland, I., Green, M.R. and Newsham, I.F. (1999) A Novel Member of the NF2/ERM/4.1 Superfamily with Growth Suppressing Properties in Lung Cancer. Cancer Research, 59, 35-43.

[20] Pang, S.T., Fang, X., Valdman, A., Norstedt, G., Pousette, A., Egevad, L. and Ekman, P. (2004) Expression of Ezrin in Prostatic Intraepithelial Neoplasia. Urology, 63, 609-612. http://dx.doi.org/10.1016/j.urology.2003.09.068

[21] Helander, T.S., Carpén, O., Turunen, O., Kovanen, P.E., Vaheri, A. and Timonen, T. (1996) ICAM-2 Redistributed by Ezrin as a Target for Killer Cells. Nature, 382, 265-268. http://dx.doi.org/10.1038/382265a0

[22] Shen, Z.Y., Xu, L.Y., Li, E.M., Li, J.T., Chen, M.H., Shen, J. and Zeng, Y. (2003) Ezrin, Actin and Cytoskeleton in Apoptosis of Esophageal Epithelial Cells Induced by Arsenic Trioxide. International Journal of Molecular Medicine, 12, 341-347.

[23] Kondo, T., Takeuchi, K., Doi, Y., Yonemura, S., Nagata, S. and Tsukita, S. (1997) ERM (Ezrin/Radixin/Moesin)Based Molecular Mechanism of Microvillar Breakdown at an Early Stage of Apoptosis. Journal of Cell Biology, 139, 749-758. http://dx.doi.org/10.1083/jcb.139.3.749

[24] Ramoni, C., Luciani, F., Spadaro, F., Lugini, L., Lozupone, F. and Fais, S. (2002) Differential Expression and Distribution of Ezrin, Radixin and Moesin in Human Natural Killer Cells. European Journal of Immunology, 32, 3059-3065. http://dx.doi.org/10.1002/1521-4141(200211)32:11<3059::AID-IMMU3059>3.0.CO;2-3

[25] Oka, M., Yoshino, S., Hazama, S., Shimoda, K., Suzuki, M. and Suzuki, T. (1992) Prognostic Significance of Regional Lymph Node Reaction after Curative Resection of Advanced Gastric Cancer. British Journal of Surgery, 79, 10911094. http://dx.doi.org/10.1002/bjs. 1800791034 
[26] Di Giorgio, A., Botti, C., Mingazzini, P., Canavese, A. and Arnone, P. (1995) Gastric Cancer: Prognosis and Lymph Node Reactivity. European Journal of Surgery, 161, 575-580.

[27] Maehara, Y., Tomisaki, S., Oda, S., Kakeji, Y., Tsujitani, S., Ichiyoshi, Y., Akazawa, K. and Sugimachi, K. (1997) Lymph Node Metastasis and Relation to Tumor Growth Potential and Local Immune Response in Advanced Gastric Cancer. International Journal of Cancer, 74, 224-228. http://dx.doi.org/10.1002/(SICI)1097-0215(19970422)74:2<224::AID-IJC15>3.0.CO;2-D

[28] Elliott, B.E., Meens, J.A., SenGupta, S.K., Louvard, D. and Arpin, M. (2005) The Membrane Cytoskeletal Crosslinker Ezrin Is Required for Metastasis of Breast Carcinoma Cells. Breast Cancer Research, 7, R365-R373. http://dx.doi.org/10.1186/bcr1006 
Scientific Research Publishing (SCIRP) is one of the largest Open Access journal publishers. It is currently publishing more than 200 open access, online, peer-reviewed journals covering a wide range of academic disciplines. SCIRP serves the worldwide academic communities and contributes to the progress and application of science with its publication.

Other selected journals from SCIRP are listed as below. Submit your manuscript to us via either submit@scirp.org or Online Submission Portal.
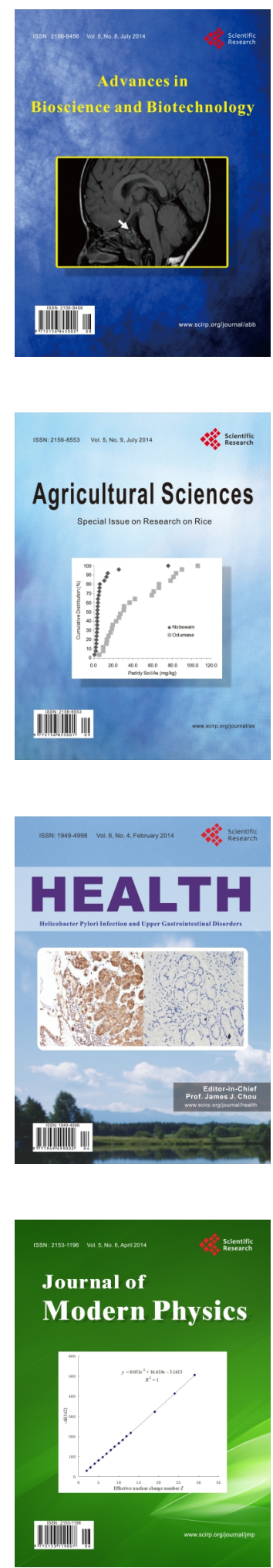
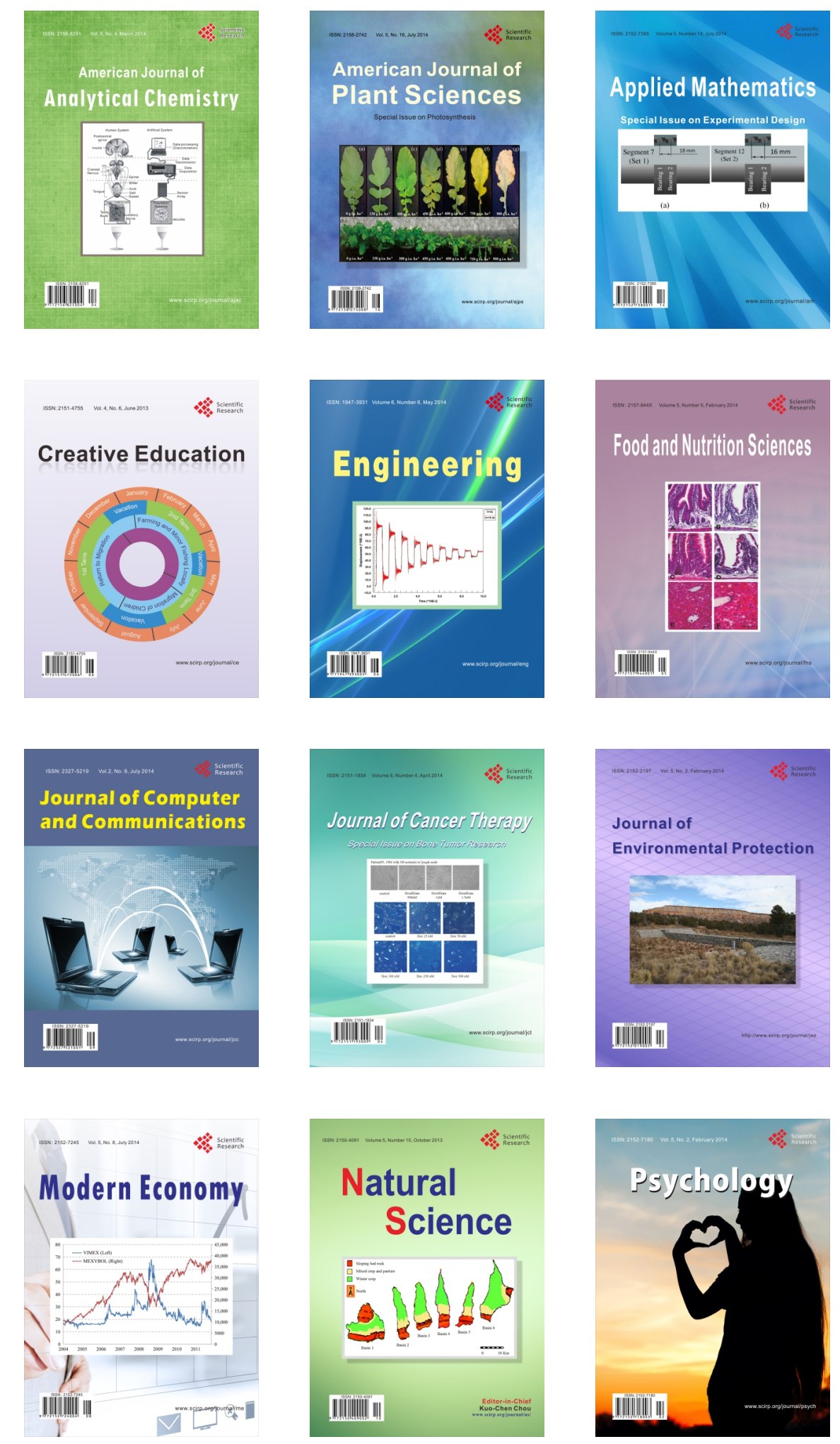